\title{
Public Health in Primary Care
}

\author{
L. Cegolon ${ }^{1,2}$, G. Mastrangelo 2 and J. H. Lange ${ }^{3}$ \\ ${ }^{1}$ Padua University, Department of Molecular Medicine, Padua, \\ 2Imperial College London, School of Public Health, S. Mary's Campus, London, \\ ${ }^{3}$ Envirosafe Training and Consultants, Pittsburgh, Pennsylvania, \\ ${ }^{1}$ Italy \\ ${ }^{2} U K$ \\ ${ }^{3} U S A$
}

\section{Introduction}

"Primary health care' is a political concept widely defined as "the mobilization of various forces in society (health professionals, institutions, lay people) around an agenda of transformation of health systems that is driven by the social values of equity, solidarity and participation"; "primary care" instead refers more specifically to technical aspects of the Care and services delivered by the health system, more toward evidence-based medicine [van Weel 2012, WHO 2008b, Kruk 2010].

Good primary care foundations furnish a number of benefits to a health system: better health for the population served, broad and equitable access to services, preparedness, an appropriate approach for disease prevention, and financial protection [Piterman 2005, WHO 2000]. Peculiarities of primary care are in fact first-contact care, ease of access, care for a broad range of health needs, continuity, and involvement of the family and community ["Declaration of Alma-Ata" 1978, Kekki 2006, Starfield 1992, van Well 2012, Kruk 2010].

Primary care systems have been frequently compared to secondary care-centered systems [Atun 2004, Engstrom 2001, Health Council of the Netherlands 2004, Macinko 2003, Starfield 2005]. Well organized primary care systems seem better able to tackle the new challenges of modern societies and the changing pattern of disease than hospital-oriented health care [WHO $2008 \mathrm{a} / \mathrm{b}$ ]. Furthermore, by guiding patients through the system, primary care physicians (PCP) become a key element to better address and respond to the needs of patients along with an understanding of a patient's concerns with their health and care, which in many ways is patient centered care [van Weel, 2012, Schafer 2011]. Indeed primary care enables access to care for the general population as well as for specific groups [Uiters 2009].

Moreover the implementation of some primary care measures (e.g. having a primary care physician as a regular health care provider, the availability of community health centers focusing on primary care, etc.) was found to be beneficial in terms of health outcomes [Franks 1998, Starfield 1992, Starfield 2005, Villalbi 1999, Kruk 2010].

A national health system founded on primary care can therefore theoretically improve the possibilities of performance because: 
- $\quad$ primary (unlike secondary) care plays an integrative role;

- $\quad$ health care is more accessible;

- $\quad$ it reinforces the relationship between primary and secondary care;

- $\quad$ care is better appropriated, as based on an evidence based approach;

- all health care resources are organized and rationalized by targeting the promotion, maintenance, and improvement of health.

\section{Primary care and public health}

Primary care and public health medicine originated in the nineteenth century, with PCPs evolving as separate clinical specialists; although, this emergence had commonalities [Piterman 2005]. This broad area of medicine developed in response to issues of urbanization, as a result of the changing needs of the community, the birth/expansion of epidemiology and integration of evidence-based medicine [van Well 2012, Hannay 1993].

However physicians with strict clinical responsibilities and lacking formal public health training did not have the management background required for public health positions. Public health medicine was responsible to set targets, allocate resources, evaluate progress, control communicable diseases, and promote health. Public health specialists were the main source of medical advice for health authorities.

Preventive services, which most commonly include, but are not limited to, immunization, health promotion, disease prevention and family planning, were initially assigned to medical officers responsible for health in Great Britain in 1919. However, service fees being collected by PCPs to provide this preventive care at the same time were encouraged as well [BMA 1993, Hannay 1993].

Primary care and public health medicine have been pursuing different paths, with PCPs having little epidemiology training and public health doctors hardly noting how PCPs were becoming more formally responsible for promoting health and preventing disease in Great Britain [UK Faculty of Public Health 1992].

The relevance of primary care in modern health systems can be perceived by the budget recently allocated by the British government into the Primary Care Trusts (PCT), the centre of the UK National Health System (NHS) responsible for spending around $75-80 \%$ of the total NHS budget [NHS 2010].

The paths of primary care and public health medicine have recently come closer: epidemiology was given credibility by clinical contact, and PCPs were made responsible for health promotion and disease prevention for the first time at the end of last century in Great Britain [Morrell 1991]. In the attempt to further attenuate these barriers postgraduate master's courses became available to PCPs and public health physicians were appointed managers at primary care services [Hannay 1993]. Nowadays both PCPs and public health doctors are responsible for preventing disease and promoting health. PCPs deal not only with the clinical management of the general community, but they also serve as front line public health officers. Today PCPs need to work within the broader context of "primary health care", requiring approach of medical care for individual patients combined with health promotion of populations [Hannay 1993]. Also, the integration of primary care and 
public health is important for tackling health inequalities, especially in areas with low social cohesion.

\section{Preventive medicine and health promotion in primary care}

As cost containment occurred in health care today there has been a shift from curative toward preventive medicine, with the aim of keeping and maintaining health rather than waiting until illness occurs to treat the patient.

Preventive care's main focus is on diseases prevention, which also requires skills in populations and community medicine beside clinical medicine. However, as they see the individual rather than the population many PCPs do not receive proper training in preventative medicine.

Albeit the ultimate target is the individual, either public health services or primary care clinical facilities could take responsibility for organizing primary prevention programs (e.g. health education or immunization campaigns), secondary prevention programs (e.g. screening or targeted health education) and tertiary prevention programs (e.g. health surveys to document unmet needs) [Starfield 1996].

\subsection{Non communicable diseases}

Beside the positive aspect that most people nowadays live longer, the ageing population in developed countries is generating a number of relevant consequences: health issues have today shifted from acute/communicable diseases to chronic and long-term conditions, as well as being lifestyle related [Schafer 2011]. Non-communicable diseases (NCD) represent a significant and unfortunately growing burden worldwide. Chronic conditions as neuropsychiatric disorders, cardiovascular disease and cancer account for most of the burden of disease [WHO 2008c]. In the past NCD mainly afflicted developed countries, but nowadays they have become a major health problem in the developing world too and will become even more widespread. Developing countries are indeed shifting towards a western lifestyle of unhealthy diet and physical inactivity and this will enhance the rate of NCDs [Wagner 2011, Lam 2012, Hu 2011]. Although some conditions do not cause death, it is important to take non-fatal conditions into account, when assessing the causes of loss of health in populations and the disability-adjusted life-years (DALYs) lost [WHO 2012a]. These factors are critical in enhancing the quality of life. Moreover it is important to note that chronic disorders appear to be correlated with each other, as suggested for cardiovascular diseases (CVDs) and neuropsychiatric conditions [Preisig 2011].

For the prevention and management of chronic conditions there is evidence that primary care is more cost-effective as compared to secondary care [Baicker 2004, Franks 1998; Welch 1993]. The integration of primary care, social care and family context of patients is an ideal approach to support people in self-managing their long-term conditions and to facilitate their living longer at home and in the community [Boerma 1998, Gress 2009].

CVD prevention is a good example in illustrating how primary care could be effective in disease prevention. 
Risk factors for CVDs are established; although, some of them are not modifiable (namely age, sex, genetics), for others much can be done in terms of health promotion to eliminate/attenuate the underlying risk [Mitchell 2010]. Smoking, poor diet and lack of physical activity are indeed the main causes for CVDs. The consequences of an unhealthy life style are well known: overweight; unbalanced ratio total cholesterol/HDL and elevated blood pressure [Katzmarzyk 2004].

Reduction of CVD risk can be effectively accomplished by smoking cessation, a reduced intake of saturated fatty acids (that will ultimately decrease the level of LDL and total cholesterol), a reduced salt intake (beneficial for hypertension) and consuming fruits, vegetables and foods rich in fibers and micronutrients that can be protective against CVDs. An hypo-caloric diet along with physical activity are also protective against obesity and may result in improvement of the cardiovascular system [Britton 2011]. Primary care is an ideal setting to efficiently deliver health education programs aiming to target all the above preventive measures, thanks to the continuous, privileged and long-running clinical contact of PCPs with their patients. One of the problems today has been to prescribe statins as a substitute, from a practical prospective, rather than addressing the underlining causes (e.g. obesity).

Drinking (alcohol) education and smoking cessation are reportedly difficult tasks to achieve. Despite numerous advances in tobacco-dependence treatment, U.S. adult smoking prevalence and quit rates have indeed stalled [Abrams 2007, Orleans 2007, Gollbust 2008]. According to Levy [2010] the annual smoking cessation without any intervention is estimated as being $4.3 \%$, reaching a rate of $4.5-10 \%$ with corporate health education campaigns requiring great effort and resources. Furthermore relapse rates after cessation are reported to be as high as cessation according to Hughes [2008], Hajek [2009] and Anderson [2009]. Yet efforts to prevent teens from taking up smoking have shown no evidence of long-term effectiveness [Wiehe 2005]. This is also seen for some occupational groups (e.g. asbestos abatement workers) where there has been no change in smoking rates over the last 20 years despite strong and repeated warnings and education [Lange 2011].

Furthermore prevalence of binge and heavy drinking among adults in the United States has been practically constant from 1993-2009, with approximately 5\% of the total population drinking heavily, while $15 \%$ of the population binge drink [Centers for Disease Control and Prevention - CDC 2012]. According to a review conducted by Foxcroft [2003] about the effectiveness of short- and medium-term primary intervention for alcohol misuse in young people, no firm conclusions have proven to be possible. Health education campaigns have failed to achieve significant public health results over time in reducing alcohol misuse.

New corporate strategies should therefore be planned to tackle smoking and alcohol misuse, combining health education campaigns involving different key figures (PCPs, pharmacists, the media, school teachers, counselors) with Government measures such as sales regulation and taxation. Moreover recent recommendations from the WHO indicate workplace health promotion as a pre-requisite for sustainable social and economic development for nations as a strategy for prevention [WHO 2012b]. As people spend more time at work today it is also 
important to involve occupational physicians in these multi-agency teams aiming at health promotion.

The workplace is in fact an environment where:

- $\quad$ a substantial percentage of the general population accrues;

- $\quad$ informal leaders and officials are delegated to promote health and safety at work;

- individuals (workers) are more receptive to health education.

Hence the workplace health promotion would enable to reach all of those individuals with difficulties in seeing their PCPs during their working hours. However PCPs remain essential figures to deal with the rest of the population, especially elderly and children.

Although not mentioned in the WHO Comparative Risk Assessment (CRA) module of the Global Burden of Disease [Ezzati 2002, The Lancet 2011], the ethnical background [CruzFlores 2011] and the educational level and socio-economic status [Agardh 2011] of patients appear to be correlated with chronic conditions or influencing other risk factors as smoking [Harris 2011] or obesity [Seidell 1997]. Health education should therefore cautiously be planned considering these variables.

Another aspect that cannot be ignored by PCPs is being a "good example" for their patients in terms of health behavior. It has in fact been shown that endorsement of physical activity is more credible coming from a health professional that also practices physical activity. PCPs should practice physical activity themselves, not only for their own benefit, but also as a stimulus for their patients [Abramson 2000, Orrow 2012]. The same concept applies to smoking, drinking and diet.

Despite the need of further improvement, mortality for CVDs and in some ways diabetes in various Western countries has reached overall good results [WHO 2011, Reaven 2011, Rosamond 2012], thanks to the health care resources allocated and the public health campaigns deployed over the past years. By contrast, in many developing countries type II diabetes is growing at epidemic levels [Hu 2011, Lam 2012]. Overall, prevention of type II diabetes through health education aiming at moderate diet and lifestyle modifications should be a primary function of PCPs and falls in the basic domain of public health [Schulze 2011].

Furthermore in Eastern European countries that have attempted to transform and up-date their healthcare systems over the past two decades, just after the fall of communism, CVDs still account for the vast majority of deaths in these areas [WHO Europe 2004, WHO 2011].

Since the 1990s, policy makers in Central and Eastern Europe have supported reforms leading towards primary care [Windak 2005]. Also in other countries of Europe, such as Spain, Greece and Portugal, reforms of health systems have aimed to strengthen primary care [Campbell 2005]. There is now a strong need for evidence to monitor and support these developments in Europe.

Integrated approaches have been proposed focusing on the main common risk factors for a range of chronic conditions: CVDs, diabetes and cancer: unhealthy diet, physically inactivity and tobacco use [WHO 2012b]. 
However, the health achievements obtained for CVDs and diabetes have not been met in cancer prevention. In fact malignancies are becoming the leading cause of death in highincome countries. The crossover of cancer to heart disease mortality has indeed been recently reported in US [US National Center for Health Statistics 2006], New Zealand [New Zealand Information Service 2003], France [WHO Europe 2004,WHO Global infobase] Spain [WHO Europe 2004], Canada [Statistics Canada 2009] and Netherlands [Statistics Netherland 2008]. These figures highly suggest failing outcomes in cancer prevention combined with rather effective measures to tackle and prevent CVDs. However, environmental pollution may also be playing a factor in a lack of change or even increase for cancer rates.

As of behavioral risk, previous observational studies showed that cancer could be prevented by a high intake of fruits and vegetables; however the European Prospective Investigation into Cancer and Nutrition cohort (EPIC, 142,605 men and 335,873 women) provided evidence of a very small inverse association between fruit and vegetable intake and cancer risk [Boffetta 2010]. Likewise, in two prospective cohorts (71,910 women in the Nurses' Health study and 37,725 men in the Health Professionals' Follow-up Study) healthy eating based on a fruit and vegetable diet proved to be effective in reducing CVDs but not cancer incidence [Hung 2004]. Furthermore, as mentioned above, satisfying and long lasting results in the reduction of alcoholism and smoking cessation are hard to reach. Ex-smokers also continue to have an elevated risk of developing lung cancer for a number of years after smoking cessation [Anthonisen 2005, Ebbert 2003], probably as a result of absence of further insult on epithelial cells rather than reversal of existing disease or genetic changes [Anthonisen 2005].

Despite all this evidence, the Union for International Cancer Control (UICC) still suggested in 2005 the same key risk factors for cancer prevention: tobacco and alcohol consumption, weight/high BMI, sun exposure, and infections [UICC 2005].

Apart from trying to improve the current public health strategies against drinking and smoking, new research should be devoted towards innovative approaches for cancer prevention (e.g. chemo-prophylaxis [Hobhom 2009]) that could be applied in more effective anti-cancer health promotion campaigns.

\subsection{Communicable diseases}

Initial cases of infectious disease are usual seen at the primary care level [Hogg 2006, Glasgow 2008]. This makes the PCPs an important sentinel in disease identification and reporting. Without a good understanding of infectious disease and epidemiology, such events can be easily missed. This requires the PCP to be an investigator of infectious diseases most often without a full picture of the actual event. Such diseases have been recently shown to impact the health care industry, especially for those events involving highly infectious agents such as influenza [Winchester, 2009], tuberculosis [Sablan 2009] or Severe Acute Respiratory Syndrome (SARS) [Lange 2005]. Early detection can mitigate a disease's spread and reduce the potential of an epidemic [Wong 2005]. Although such event is uncommon on a regional or global scale, outbreaks commonly occur at the local level [Lau 2010]. Primary care can provide an invaluable contribution for the Initial identification of an outbreak. 
For example, this can be seen for occurrence of pertussis (Bordetella pertussis). Today, even many of the diseases considered to be associated with childhood are now occurring in adults (e.g. pertussis) [CDC 2003]. Here such events are generally related to a lack of preventative practice, in this case failure to adequately vaccinate or failing in determining the current status of vaccination level. This can even be extended to the occupational environment where a pertussis outbreak occurred in a group of oil refinery workers [CDC 2003].

In most cases, outbreaks at the local level are most commonly associated with food poisoning. In locations where reporting is mandatory, it has been found that actual notification is poor with a trend even declining [Day 2007]. Such practices do not allow the full realization of disease rate and can perpetuate an endemic event. This becomes even more important with the finding that there are 200 cases of gastrointestinal disease for every 1,000 registered patients a year in England [Day 2007]. However, the delay in laboratory reporting sometimes can be considerable. For example, in Australia there is a 19 day delay for Bordetella pertussis and many PCPs have a poor understanding of the time line and process, especially on its impact for controlling a communicable disease [Allen 2000]. As a result the spread of a disease can be magnified, especially one that is high communicable, as influenza [Khan 2012]. Information and reports from PCPs are key components in establishing disease registrations and surveillance along with describing events for estimating future trends [Day 2007]. As mentioned, these preventative activities apply not only to patients but those in occupations that are at risk (e.g. health-care workers, industrial populations). A lack of preventative measures at the occupational level can allow a local event (epidemic) to occur. PCPs can be effective in preventing infectious disease through health education, by informing patients on preventative practices. One of the key domains in this regard is vaccination against traditional diseases such as tetanus toxoid, hepatitis B, mumps, measles, rubella, diphtheria, polio, meningitis, Haemophilus influenza, pneumococcus, yellow fever and (more recently) varicella [Bilcke 2012]. Proper vaccination, especially against continuing and emerging-related diseases remains an important area for PCPs, frequently forgotten with consideration given to more high technology activities [Venkat 2012]. Evaluation as to whether a patient's vaccine schedule is up-to-date is a fundamental practice in primary care.

Another important mechanism to reduce the transmission of various infectious diseases is hand-washing [Bencho 2006].

\section{Environmental and occupational medicine}

Occupational diseases (e.g. particulate induced asthma) are major hazards which can mostly be prevented [Rosenblatt 2005]. Since they are most likely to be the first to encounter patients with these types of problems [Weevers 2005], PCPs are in many ways gatekeepers in recognizing and in some ways preventing environmental and occupational diseases. However, as their focus is on clinical identification and treatment of the disease, PCPs are normally not trained to recognize occupational diseases. In environmental and occupational medicine the critical point is not a clinical diagnosis of the disease, but rather the etiological diagnosis (e.g. agent of causation) [Cegolon 2010b]. The answer to four easy questions in 
occupational medicine history taking is helpful for an initial assessment of the possible disease causation [Agius 2000, Cegolon 2010b]:

- Temporal relationship: What is the time lag between the initial exposure and the start of the symptoms?

- Dose-effect (time) relationship: do the symptoms improve if the patient is not exposed any longer (e.g. if he/she changes work duties or is on holiday?

- Dose-effect relationship: do the symptoms worsen if the patient carries out specific duties or works in areas characterised by high levels of exposure?

- Strength of the association: are colleagues affected by the same symptoms related to the same exposure?

As environmental pollution and the number of chemicals/agents in the occupational environment increase, it can be hard to establish a relationship between a disease and a specific agent. This can be magnified when interactions among different exposure agents are considered. Identification of this nature is often required by regulatory and insurance agencies for compensation and future prevention [Liss 2011]. Initial assessment may be possible by the type of personal protective equipment (PPE) used by the patient; in fact there are different forms of PPE and each has varying value in providing protection against harmful agents [Health and Safety Executive -HSE 1999, Garrod 2003, Agius 2000, La Dou 2008]. Much of this can be accomplished through obtaining an adequate medical history.

Most of these diseases are duration related; therefore, a history of time and concentration exposure is required to suspect an environmental and occupational disease/diagnosis. Nevertheless, recognition and understanding the causation of occupational diseases is critical, as the latency period often makes it difficult to assess the exposure.

What is of even greater importance is the prevention of future disease cases in the population and origin of the patient. This practice is only slightly within the realm of primary care. However, PCPs are an important resource to alert others more directly responsible for preventing such occurrences.

This also requires an understanding of changes in recognizable diseases related to the work environment, as the case of asbestos in the western world. Historically, asbestos has been considered a contributor to occupational respiratory disease. However, due to controls and better understanding of this mineral agent, those engaging in its abatement (asbestos abatement workers) have low exposure and little or even no risk of developing disease directly as a result of this agent [Lange 2011]. What have become of importance in disease causation for this occupational population are confounders such as their personal habits (e.g. smoking) and risk characteristics, aspects so far mostly ignored with focus on actual asbestos exposure. These concepts are continually changing and require PCPs to keep up-todate their current knowledge in the areas they practice. PCPs must therefore assess the actual disease risk through evidence-based medicine.

\section{Global health}

It has been estimated that environmental causes account for about $25 \%$ of global related diseases [Gehle 2011]. Global warming and an increased level of pollutants on a world-wide 
basis are changing the biometric characteristics and the environment in various geographical locations in an unpredicted manner. Change in the global environment has therefore brought about a difference in diseases seen in primary care. For example increased heat stress and related events not normally seen in different areas are now emerging [Hajat 2010]. Depletion of the stratospheric ozone layer has led to increased solar UV-B radiation at the surface of the earth leading to increased human exposure to UV-B radiation with consequent detrimental and beneficial effects on health, most notably on the eye (cataract) and the skin (cancer) [Norval 2011]. A rise in infectious disease rates will also be likely impacted by global and regional warming/pollution [Semenza 2011]. Furthermore, the extent and severity of asthma is increasing, requiring a larger number of visits and more aggressive treatments [Rosenblatt 2005]. This change in rate and severity cannot be offset by immunization and may even be magnified by changing patterns of influenza and other infectious diseases. These new scenarios will increase the primary care workload, as these conditions will be handled in many ways by PCPs. Many of the culprits of this climate changes are beyond controls of medicine, but the outcomes will have to be dealt with by those at the front line.

As populations increase, primary care will grow in importance, as for some it may become the only form of care accessible. Furthermore primary care will also likely change its role, as may need their PCPs to acquire additional sub-specialization.

For instance the health effects of hot weather are quickly becoming a global public health challenge of this century [Hajat 2010]. As heat related diseases are largely avoidable, various public health protection measures have been put in place in some cities across the world, with particular emphasis on preventive strategies for susceptible individuals [Keatinge 2003]. In particular it is fundamental for physicians and pharmacists to be prepared for effective prevention, first-aid treatment and knowledge of possible adverse effects of medicines prescribed during hot weather [Hajat 2010].

Overall, PCPs in the future will have to include a more comprehensive (global) approach in the management and diagnosis of diseases, as in some cases a condition is unrelated to the actual individual but their environment. The old approach treating a condition without a holistic view not considering possible underlying causes seems to be obsolete.

\section{Research in primary care}

Research in primary care is becoming more relevant, as it offers the opportunity to examine huge samples, more representative of the general population. PCP networks in many countries allow collection of large national electronic databases to be employed for several purposes: academic primary care research; disease monitoring; population's needs assessment; tracking changes over time (trends) and in response to interventions; pharmacological-vigilance; health care evaluation; infectious disease surveillance; outbreak investigation; clinical trials; etc [Medicine and Health Care Products Regulatory Agency - MHRA]. Most electronic health databases are used in pharmaco-epidemiologic studies [Schneeweiss 2005]. The General Practitioners Research Database (GPRD) for instance is an international electronic medical record system including basic demographic details, medical records, drug history, and prevention records. In addition to its comprehensive contents, linkages to external registries (e.g. Cancer Registry or Hospital Episodes Statistics database) are also made possible by sophisticated encryption procedures [Majeed 2004]. Access barriers to these national electronic databases should be reduced in order to make more data available for research. These data 
have great potential as research tools and can help in maximizing the outputs: in particular academic research and health care de;ivery [Chun Chen 2011]

Primary care research allows a more pragmatic approach than conventional randomized control trials (RCT, often funded by pharmaceutical companies and based at tertiary centres), as it provides a more realistic assessment of drug use and reflects a shared decision between PCPs and their respective patients. Patients' experiences with drugs in "real world" clinical practices are indeed particularly relevant. Furthermore primary care doctors rely on clinical judgment and experience to weigh the risks and benefits of trials [David 2008].

\section{Primary care in prospects}

Despite primary care aims at equity in the access and distribution of health services [Wilkinson 1990], recent research suggested that PCPs treating wealthier and more educated patients may be better trained clinically and may have more access to important clinical resources than physicians treating less affluent patients. Further research should be conducted to address the extent to which these differences may be responsible for disparities in health care [Bach 2004].

In western societies we are assisting a progressive individualization, with citizens becoming more autonomous in their decisions and less dependent and linked to their social environment [Mills 2007]. These societal developments are bringing people to stay more at home and being independent, but are also weakening social relations and cohesions [Schafer 2011].

Patients nowadays are more knowledgeable about medicine, demanding a higher standard of care and willing to get involved into health care decision making. More information is indeed nowadays available, especially through the internet [Groenewengen 2008, Schafer 2011].

The increasing relevance of markets in health care is having an impact on the competition at work, with health care workers expressing less trust in their colleagues and as a result generating a more fragmented work environment [Groenewengen 2008]. This is not helpful for the management, for instance, of chronic and long term conditions where integration and cooperation between the various health care providers involved is recommended. Cooperation, good relationships between primary and secondary care and integration of care between organizations are more important than competition [Schafer 2011].

There is considerable variation in the organization of primary care across Europe. Albeit this is positive as countries can learn from each other, there is also a need for a European infrastructure to support training and integrate primary care action. For instance some European countries are still lacking academic primary care programs and academic institutions, invaluable instruments to monitor health outcomes and evaluate health systems [De Maeseneer 2010].

Modern primary care needs to evolve from a family business into a larger, corporate organization, both at the national and international level [Schafer 2011].

\section{References}

Ab Rahman A, Ab Rahman R, Ibrahim MI, et al. Knowledge of sexual and reproductive health among adolescents attending school in Kelantan, Malaysia. Southeast Asian J Trop Med Public Health. 2011;42:717-25. 
Abrams D. Comprehensive smoking cessation policy for all smokers: systems integration to save lives and money. In: Bonnie RJ, Stratton K, Wallace RB, eds. Ending the tobacco problem: a blueprint for the nation. Washington: The National Academies Press. 2007.

Abramson S, Stein J, Schaufele M, Frates E, Rogan S. Personal exercise habits and counseling practices of primary care physicians: a national survey. Clin J Sport Med. 2000;10:40-8.

Agardh EE et al. Burden of type 2 diabetes attributed to lower educational levels in Sweden. Population Health Metrics. 2011, 9:60.

Agius R: Taking an Occupational History. Health Environment \& Work 2000 [http://www.agius.com/hew/resource/occhist.htm]. (updated in January 2010; accessed on 23 July 2011).

Allen CJ, Ferson MJ. Notification of infectious diseases by general practitioners: a quantitative and qualitative study. Med J Aust. 2000;172:325-8.

Anderson CM, Yip R, Henschke CI, Yankelevitz DF, Ostroff JS, Burns DM. Smoking Cessation and Relapse during a Lung Cancer Screening Program. Cancer Epidemiol Biomarkers Prev. 2009;18: 3476-83.

Anthonisen NR, Skeans MA, Wise RA, Manfreda J, Kanner RE, Connett JE .The Effects of a Smoking Cessation Intervention on 14.5-Year Mortality. Ann Intern Med. 2005;142: 233-239.

Atun, R. What are the advantages and disadvantages of restructuring a health care system to be more focused on primary care services? London: Health Evidence Network. 2004.

Bach PB, Hoangmai H, Schrag D, Tate RC; Hargraves JL. Primary Care Physicians Who Treat Blacks and Whites. N Eng J Med. 2004;351: 575-584.

Baicker K, Chandra A. Medicare spending, the physician workforce, and beneficiaries' quality of care. Health Affairs (Millwood)(Suppl. Web Exclusives), 2004; W184W197.

Bencho V, Schejbalova M. From Ignaz Semmelweis to the present: crucial problems of hospital hygiene. Indoor and Built Environment. 2006;15:3-8.

Bilcke J, Ogunjimi B, Marais C, et al. The health and economic burden of chickenpox and herpes zoster in Belgium. Epidemiol Infect. 2012;10:1-14.

BMA Board of Science and Education. Clinical hyperbaric medicine facilties in the UK London: BMA, 1993.

Boerma WGW and Fleming DM. The Role of General Practice in Primary Health Care. London: World Health Organization, 1998.

Boffetta P et al. Fruit and Vegetable Intake and Overall Cancer Risk in the European Prospective Investigation Into Cancer and Nutrition (EPIC ). J Natl Cancer Inst. 2010; 102: 529-537.

Britton A, Brunner E, Kivimaki M, Shipley MJ. Limitations to functioning and independent living after the onset of coronary heart disease: what is the role of lifestyle factors and obesity? Eur J Public Health. 2011; doi: 10.1093/eurpub/ckr150.

Campbell JL, Medive J and Timmermans A. Primary care and general practice in Europe: West and South. In: Jones R, Britten N, Culpepper L et al (eds) Oxford Textbook of Primary Medical Care. Oxford: Oxford University Press, 2005, pp. 70-3. 
Cegolon L, Miatto E, Bortolotto M, et al. Body piercing and tattoo: awareness of health related risks among 4,277 Italian secondary school adolescents. BMC Public Health. 2010a, 10:73

Cegolon L, Lange JH, Mastrangelo G. The Primary Care Practitioner and the diagnosis of occupational diseases. BMC Public Health. 2010b, 10:405

Center for Disease Prevention and Control (CDC, 2012). Alcohol \& Public Health. Available at: www.cdc.gov/alcohol/ (accessed on 12 April 2012).

Centers for Disease Control. Pertussis outbreak among adults at an oil refinery--Illinois, August-October 2002. MMWR. 2003;10:1-4.

Chun Chen Y, Ching Wu J, Haschler I, Majeed A, Ji Chen T, Wetter T. Academic Impact of a Public Electronic Health Database: Bibliometric Analysis of Studies Using the General Practice Research Database. PLos One 2011; 6 (6): e21404.

David SP, Munafò MR. Smoking cessation in primary care. BMJ. 31 may 2008 | 3361201. Cruz-Flores S, Rabinstein A, Biller J, Elkind MS, et al. Racial-ethnic disparities in stroke care: the American experience: a statement for healthcare professionals from the American Heart Association/American Stroke Association. Stroke. 2011 Jul;42(7):2091-116.

Day F, Sutton G. General practitioner notifications of gastroenteritis and food poisoning: cause for concern. J Public Health (Oxf). 2007;29:288-91.

Declaration of Alma-Ata. In International conference on primary health care, Alma-Ata, USSR. 1978.

De Maeseneer J, Willems S. New Challenges Require New Types of Health Services Research. Abstract. Third bi-annual conference European Forum for Primary Care: The Future of Primary Health Care in Europe III, 2010.

Ebbert JO, Yang P, Vachon CM, Vierkant RA, Cerhan JR, Folsom AR, Sellers TA. Lung Cancer Risk Reduction After Smoking Cessation: Observations From a Prospective Cohort of Women. J Clin Oncol. 2003; 21:921-926.

Engstrom S, Foldevi M, Borgquist L. Is general practice effective? A systematic literature review. Scandinavian Journal of Primary Health Care. 2001; 19,131-144.

Ezzati M, Lopez AD, Rodgers A. Vander Hoorn, S., Murray, C. J., Selected major risk factors and global and regional burden of disease. Lancet. 2002. 360:1347-60.

Foxcroft DR , Ireland D, Lister-Sharp DJ, Lowe G, Breen R. Longer-term primary prevention for alcohol misuse in young people: a systematic review. Addiction. 2003; 98:397411.

Franks P, Fiscella K. Primary care physicians and specialists as personal physicians. Health care expenditures and mortality experience. Journal of Family Practice. 1998; 47: 105-109.

Garrod ANI, Rajan Sithamparanadarajah R: Developing COSHH Essentials: Dermal Exposure, Personal Protective Equipment and First Aid. Ann Occup Hyg 2003. 47:577-588.

Gehle KS, Crawford JL, Hatcher MT. Integrating environmental health into medical education. Am J Prev Med. 2011;41(4 Suppl 3):S296-301.

Glasgow N. Systems for the management of respiratory disease in primary care - an international series: Australia. Prim Care Respir J. 2008;17:19-25.

Gollust S, Schroeder S, Warner K. Helping smokers quit: understanding the barriers to utilization of smoking cessation services. The Millbank Quarterly. 2008;86:601-27. 
Gress S, Baan CA, Calnan M et al. Co-ordination and management of chronic conditions in Europe: the role of primary care. Position paper of the European Forum for Primary Care. Quality in Primary Care. 2009;17:75-86.

Groenewegen PP. Nursing as grease in the primary care innovation machinery. Quality in Primary Care. 2008;16:313-14.

Hajek P, Stead LF, West R, Jarvis M, Lancaster T. Relapse prevention interventions for smoking cessation (Review). The Cochrane Library. 2009; Issue 1. Available at: www.thecochranelibrary.com (accessed on 9 July 2010).

Hannay DR. Primary care and public health. BMJ. 1993; 307: 516-517.

Harris JR, Huang Y, Hannon PA, Williams B. Low-socioeconomic status workers: their health risks and how to reach them. J Occup Environ Med. 2011;53:132-8.

Health Council of the Netherlands. European primary care. The Hague. 2004.

Health and Safety Executive (HSE). COSHH Essentials--easy steps to control chemicals (HSG 193). Sudbury: HSE Books; 1999. ISBN 0717.

Hajat S, O'Connor M, Kosatsky T. Health effects of hot weather: from awareness of risk factors to effective health protection. The Lancet. 2010; 375: 856-63.

Hobhom U. Toward general prophylactic cancer vaccination. Bioessays. 2009;31:1071-9.

Hogg W, Huston P, Martin C, Soto E. Enhancing public health response to respiratory epidemics: are family physicians ready and willing to help? Can Family Physician. 2006;52:1254-60.

$\mathrm{Hu}$ FB. Globalization of diabetes: the role of diet, lifestyle, and genes. Diabetes Care. 2011;34:1249-57.

Hughes JR, Peters EN, Naud S. Relapse to Smoking After 1 Year of Abstinence: A Metaanalysis. Addict Behav. 2008; 33: 1516-1520.

Hung HC, Joshipura KJ, Hu FB, et al. Fruit and Vegetable Intake and Risk of Major Chronic Disease. J Nat Cancer Inst. 2004; 96: 1577-84.

Keatinge WR. Death in heat waves. BMJ. 2003; 327: 512-13.

Katzmarzyk PT, Church TS, Blair SN. Cardiorespiratory fitness attenuates the effects of the metabolic syndrome on all-cause and cardiovascular disease mortality in men. Arch Intern Med. 2004;164:1092-7.

Kekki, P. Primary health care and the millennium development goals: Issues for discussion. Helsinki: University of Helsinki. 2006.

Khan K, McNabb SJ, Memish ZA, et al. Infectious disease surveillance and modelling across geographic frontiers and scientific specialties. Lancet Infect Dis. 2012:12:222-30.

Kruk ME, Porignon D, Rockers PC, Van Lerberghe W. The contribution of primary care to health and health systems in low- and middle-income countries: A critical review of major primary care initiatives. Social Science \& Medicine 70 (2010) 904-911.

La Dou J. Current Occupational and Environmental Medicine . 4th edition. McGraw-Hill Publishers, New York, NY; 2008.

Lam DW, Le Roith D. The worldwide diabetes epidemic. Curr Opin Endocrinol Diabetes Obes. 2012;19:93-6.

Lange JH. SARS, emerging diseases, healthcare workers and respirators. J Hosp Infect. 2005;60:293.

Lange JH, Mastrangelo G, Cegolon L. Asbestos abatement workers versus asbestos workers: exposure and health-effects differ. Int J Occup Med Environm Health 2011; 24:418-9.

The Lancet (Editorial). Stemming the global tsunami of cardiovascular disease. The Lancet. 2011. 377 (February 12): 529-532. 
Lau JT, Griffiths S, Choi KC, Lin C. Prevalence of preventive behaviors and associated factors during early phase of the H1N1 influenza epidemic. Am J Infect Control. 2010;38:374-80.

Levy TD, Graham AL, Mabry PL, Abrams DB, Orleans TB. Modeling the Impact of Smoking-Cessation Treatment Policies on Quit Rates. Am J Prev Med. 2010; 38(3S): S364-S372.

Liss GM, Buyantseva L, Luce CE, et al. Work-related asthma in health care in Ontario. Am J Ind Med. 2011;54:278-84.

Macinko J, Starfield B, Shi L. The contribution of primary care systems to health outcomes within Organization for Economic Cooperation and Development (OECD) countries, 1970-1998. Health Services Research. 2003; 38: 831-865.

Majeed A. Sources, uses, strengths and limitations of data collected in primary care in England. Health Statistics Quarterly 2004; 21: 5-14.

Medicine and Health Care Products Regulatory Agency. GPRD. Available at: http://www.gprd.com/home/

Morrell DC. Role of research in development of organisation and structure of general practice. BMJ. 1991;302:1313-6.

Mills M. Individualization and the life course: towards a theoretical model and empirical evidence. In: Howard C (ed) Contested Individualization: political sociologies of contemporary personhood. Basingstoke: Palgrave MacMillan, 2007: 61-79.

Mitchell JA, Bornstein DB, Sui X, et al. The impact of combined health factors on cardiovascular disease mortality. Am Heart J. 2010;160:102-8.

NHS (2010). What is a PCT? NHS Walsall. Available at: www.walsall.nhs.uk/about_us/whatisapct.asp (accessed on 7 February 2012).

New Zealand Health Information Service. Mortality and Demographic Data 2002 and 2003. Ministry of Health. 2006; available at: http:/ / www.nzhis.govt.nz/moh.nsf/pagesns/528 (accessed on 15 Jan 2012).

Norval M, Lucas RM, Cullen AP, et al. The human health effects of ozone depletion and interactions with climate change. Photochem Photobiol Sci. 2011;10:199-225.

Orleans CT. Increasing the demand for and use of effective smoking-cessation treatments reaping the full health benefits of tobacco-control science and policy gains - in our lifetime. Am J Prev Med. 2007;33(6S):S340-8.

Orrow G, Kinmonth AL, Sanderson S et al., Effectiveness of physical activity promotion based in primary care: systematic review and meta-analysis of randomized controlled trials. BMJ. 344:e1389.

Piterman L, Koritsas S. Part I; General practitioner-specialist relationship. Intern Med 2005;35:430-4.

Preisig M, Waeber G, Mooser V, Vollenweider P. PsyCoLaus: mental disorders and cardiovascular diseases: spurious association? Rev Med Suisse. 2011; 7: 2127-9.

Reaven GM. Insulin resistance: the link between obesity and cardiovascular disease. Med Clin North Am. 2011 95:875-92.

Rosenblatt RA. Ecological change and the future of the human species: can physicians make a difference? Ann Fam Med. 2005;3:173-6.

Rosamond WD, Chambless LE, Heiss G, Mosley TH, Coresh J, Whitsel E, Wagenknecht L, $\mathrm{Ni} \mathrm{H}$, Folsom AR. Twenty-Two Year Trends in Incidence of Myocardial Infarction, CHD Mortality, and Case-Fatality in Four US Communities, 1987 to 2008. Circulation. 2012 Mar 15. [Epub ahead of print]. 
Sablan B. An update on primary care management for tuberculosis in children. Curr Opin Pediatr. 2009;21:801-4.

Schafer W. Groenewegen PP, Hansen J, Black N. Priorities for health services research in primary care. Quality in Primary Care. 2011;19:77-83.

Schneeweiss S, Avorn J. A review of uses of health care utilization databases for epidemiologic research on therapeutics. J Clinical Epid. 2005; 58:323-33.

Schulze MB, Hu FB. Primary prevention of diabetes: what can be done and how much can be prevented? Ann Rev Public Health. 2005:26:445-67.

Seidell JC, Flegal KM. Assessing obesity: classification and epidemiology. Br Med Bull. 1997;53:238-52.

Semenza JC, Suk JE, Estevez V, et al. Mapping Climate Change Vulnerabilities to Infectious Diseases in Europe. Environ Health Perspect. 2011;120:385-92.

Starfield B, Shi L, Macinko, J. Contribution of primary care to health systems and health. Milbank Q. 2005: 83:457-502.

Starfield B. Public Health and Primary Care: A Framework for Proposed Linkages. American Journal of Public Health. 1996; 86:1365-89.

Starfield, B. Primary care: Concept, evaluation, and policy. New York: Oxford niversity Press.1992.

Statistics Canada. Available at: www.statcan.gc.ca (accessed on 19 August 2010; updated on 3rd Feb 2009).

Statistics Netherlands. Cancer number one cause of death in 2008. Available at: www.cbs.nl/enGB/menu/themas/gezondheidwelzijn/publicaties/artikelen/arch ief/2009/2009-2687-wm.htm (Accessed on 19 August 2009; updated on 3 February 2009).

U.S. National Center for Health Statistics. Death by major causes, 1960-2005. National Vital Statistics Reports. 2006, vol.54 (19). Available at: http:// www.infoplease.com/ipa/A0005124.html (accessed on 12 July 2010).

UICC (2005). Cancer can be prevented too. Available at:

http://www.worldcancercampaign.org/index.php?option=com_content\&task=vie w\&id=273\&Itemid=586 (accessed on 15 Jan 2012).

Uiters E, Deville W, Foets $\mathrm{M}$, et al. Differences between immigrant and non-immigrant groups in the use of primary medical care; a systematic review. BMC Health Services Research. 2009;9:76.

UK Faculty of Public Health Medicine. UK levels of health. London: FPHM, 1992.

Van Weel C, Schers H, Timmermans A. Health care in the Netherlands. Am Board Fam Med 2012;25 (Suppl 1):S12-7.

Venkat A, Hunter R, Hegde GG, et al. Perceptions of Participating Emergency Nurses Regarding an ED Seasonal Influenza Vaccination Program. J Emerg Nurs. 2012;38:22-9.

Villalbi, JR, Guarga A, Pasarin MI, et al. An evaluation of the impact of primary care reform on health. Aten Primaria. 1999; 24:468 474.

Wagner $\mathrm{KH}$, Brath $\mathrm{H}$. A global view on the development of non communicable diseases. Prev Med. 2011 [Epub ahead of print].

Weevers HJ, van der Beek AJ, Anema JR, et al. Work-related disease in general practice: a systematic review. Fam Pract. 2005;22:197-204.

Welch WP, Miller ME, Welch HG, et al. Geographic variation in expenditures for physicians' services in the United States. New England Journal of Medicine, 1993; 328:621-627. 
WHO (2012). Metrics: Disability-Adjusted Life Year (DALY). Health Statistics and Health Information Systems. Available at:

www.who.int/healthinfo/global_burden_disease/metrics_day/en/ (accessed on 7 February 2012).

WHO (2011). Mortality, Cardiovascular diseases and diabetes, deaths per 100,000. Global Health Observatory Data Repository. Available at:

www.who.int/ghodata/?vid=10011 (accessed on 7 February 2012).

WHO (2008). Integrating mental health into primary care: A global perspective. Geneva: WHO. whqlibdoc.who.int/publications/2008/9789241563680_eng.pdf (accessed on April 4, 2012).

WHO (2008a) The world health report. primary health care: now more than ever. Available at: http:/ / books.google.it/books?hl=it\&lr=\&id=q-EGxRjrIo4C\&oi=fnd\&pg=PR8\&dq =who+primary+care+more+than+ever\&ots=YbrEXUILFp\&sig=LpiHNS75aXPoaTM6oOSKRVoitE\#v=onepage\&q=who $\% 20$ primary $\% 20$ care $\% 20$ more $\% 20$ than $\% 2$ 0ever\&f=false (accessed on 15 January 2012).

WHO (2008b). World Health Report 2008: Primary health care - Now more than ever. Geneva: WHO. www.who.int/whr/2008/en/index.html (accessed April 4, 2012)

WHO. Global burden of disease (2004 update). Available at: http://www.who.int/healthinfo/global_burden_disease/GBD_report_2004update _full.pdf (accessed on 15 Jan 2012).

WHO Europe 2004. Highlights on Heath in France. Available at: http://www.euro.who.int/_data/assets/pdf_file/0020/103853/E88547.pdf (accessed on 15 Jan 2012),

WHO Global Infobase: proportional mortlality. Available at: https:/ /apps.who.int/infobase/Mortality.aspx (accessed on 15 Jan 2012).

WHO (2012a). Workplace Health Promotion. Available at: http://www.who.int/occupational_health/topics/workplace/en/ (accessed on 15 Jan 2012).

WHO (2000). World health report: health systems improving performance. Geneva, Switzerland. Available at: http://www.who.int/whr/2000/en/ (accessed on 15 Jan 2012).

Wiehe SE, Garrison MM, Christakis DA, Ebel BE, Rivara FP. A systematic review of schoolbased smoking prevention trials with long-term follow-up. J Adolesc Health. 2005;36:162-9.

Wilkinson RG. Income distribution and mortality: a 'natural' experiment. Sociol Health Illness. 1990;12:391-412.

Winchester CC, Macfarlane TV, Thomas M, Price D. Antibiotic prescribing and outcomes of lower respiratory tract infection in UK primary care. Chest. 2009;135:1163-72.

Windak A and Van Hasselt P.Primary care and general practice in Europe: Central and East. In: Jones R, Britten N, Culpepper L et al (eds) Oxford Textbook of Primary Medical Care. Oxford: Oxford University Press, 2005: 70-3.

Wong SY, Wong W, Jaakkimainen L, et al. Primary care physicians in Hong Kong and Canada--how did their practices differ during the SARS epidemic? Fam Pract. 2005;22:361-6. 


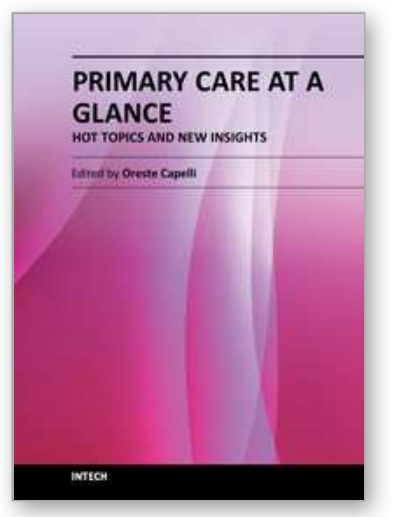

\author{
Primary Care at a Glance - Hot Topics and New Insights \\ Edited by Dr. Oreste Capelli
}

ISBN 978-953-51-0539-8

Hard cover, 446 pages

Publisher InTech

Published online 27, April, 2012

Published in print edition April, 2012

"Both among scientists and clinical practitioners, some find it easier to rely upon trivial explanations, while others never stop looking for answers". With these surprising words, Augusto Murri, an Italian master in clinical medicine, reminds us that medical practice should be a continuous journey towards knowledge and the quality of care. The book brings together contributions by over 50 authors from many countries, all around the world, from Europe to Africa, from Asia to Australia, from North to South America. Different cultures are presented together, from those with advanced technologies to those of intangible spirituality, but they are all connected by five professional attributes, that in the 1978 the Institute of Medicine (IOM) 1 stated as essentials of practicing good Primary Care: accessibility, comprehensiveness, coordination, continuity and accountability. The content of the book is organized according to these 5 attributes, to give the reader an international overview of hot topics and new insights in Primary Care, all around the world.

\title{
How to reference
}

In order to correctly reference this scholarly work, feel free to copy and paste the following:

L. Cegolon, G. Mastrangelo and J. H. Lange (2012). Public Health in Primary Care, Primary Care at a Glance Hot Topics and New Insights, Dr. Oreste Capelli (Ed.), ISBN: 978-953-51-0539-8, InTech, Available from: http://www.intechopen.com/books/primary-care-at-a-glance-hot-topics-and-new-insights/public-health-inprimary-care

\section{INTECH}

open science | open minds

\author{
InTech Europe \\ University Campus STeP Ri \\ Slavka Krautzeka 83/A \\ 51000 Rijeka, Croatia \\ Phone: +385 (51) 770447 \\ Fax: +385 (51) 686166 \\ www.intechopen.com
}

\author{
InTech China \\ Unit 405, Office Block, Hotel Equatorial Shanghai \\ No.65, Yan An Road (West), Shanghai, 200040, China \\ 中国上海市延安西路65号上海国际贵都大饭店办公楼405单元 \\ Phone: +86-21-62489820 \\ Fax: +86-21-62489821
}


(C) 2012 The Author(s). Licensee IntechOpen. This is an open access article distributed under the terms of the Creative Commons Attribution 3.0 License, which permits unrestricted use, distribution, and reproduction in any medium, provided the original work is properly cited. 